\section{Ana Munk}

Odsjek za povijest umjetnosti Filozofskog fakulteta Sveučilišta u Zagrebu

DOI:

10.17685/PERISTIL.60.13

\title{
Zoraida Demori Staničić Javni kultovi ikona u Dalmaciji
}

Književni krug Split, Hrvatski restauratorski zavod

Split - Zagreb, 2017. 344 str.
Recenzenti:

Ana Munk, Joško Belamarić

ISBN 978-953-163-443-4 (KKS), ISBN 978-953-7389-27-7 (HRZ)

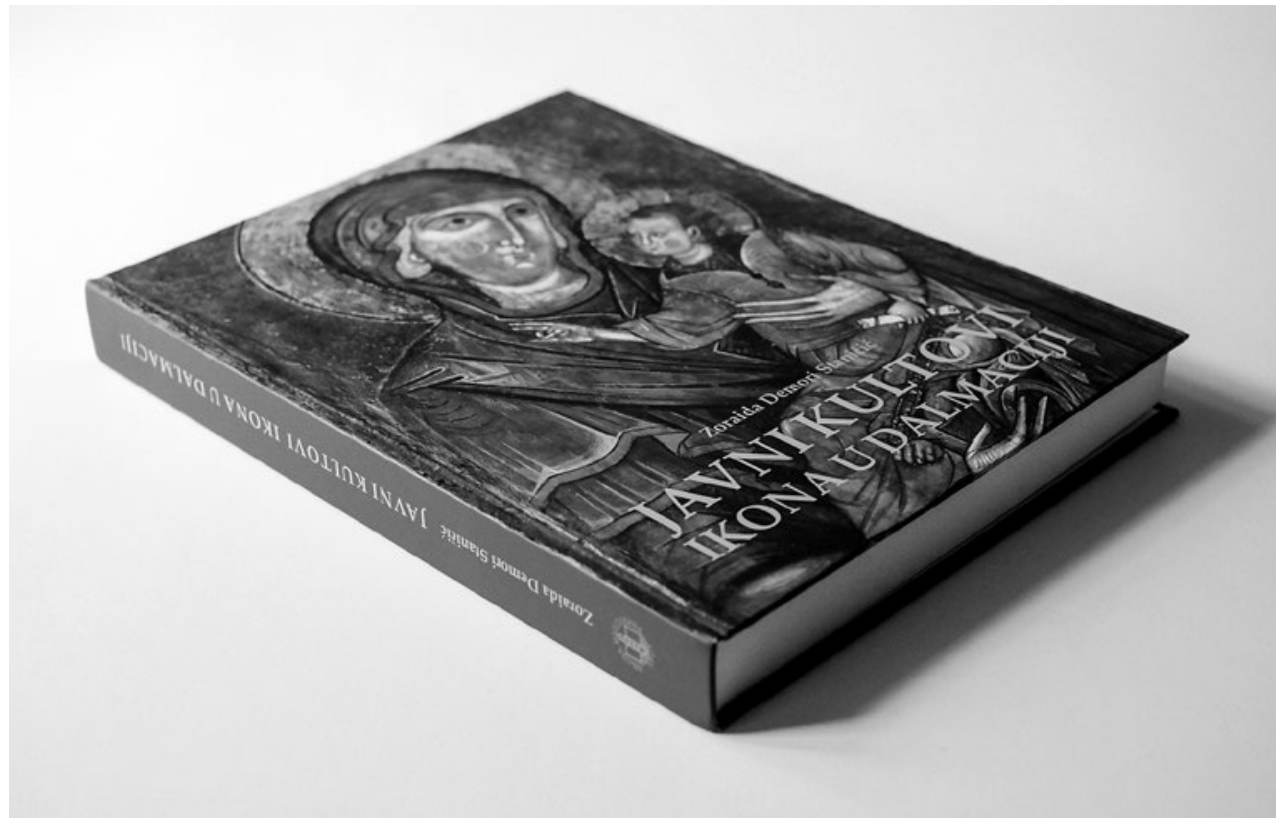

foto: Sanjin Kaštelan

Knjiga Javni kultovi ikona u Dalmaciji autorice Zoraide Demori Staničić prva je knjiga koja je objavljena na tu temu u Hrvatskoj. Kroz 294 ilustracija i na 388 stranica obrađuje se čak 108 ikona nastalih od 13. do početka 20. stoljeća, koje do sada nisu bile sustavno obradene niti interpretirane što dovoljno upućuje na važnost same teme i na doprinos koje će ovo djelo dati razvoju povijesti umjetnosti u Hrvatskoj. Knjiga se temelji na arhivskim i terenskim istraživanjima povjesničarke umjetnosti i konzervatorice koja je do sada objavila cijeli niz izvornih znanstvenih i stručnih radova na temu ikona. Dugogodišnji znanstveni rad rezultirao je cjelovitom i zaokruženom sintezom ove složene problematike. Treba medutim naglasiti da ovo djelo nije zamišljeno samo kao sistematizacija brojnih ikona koje stoljećima rese oltare dalmatinskih crkava, nego nudi i znanstveno utemeljenu interpretaciju njihove uloge $u$ vjerskom i kulturnom životu Dalmacije. Riječ je o svetim slikama „visokog statusa čašćenja“ koje su služile kao materijalna uporišta vjerskog života u Dalmaciji i prije svega funkcionirale „u kultu“ kroz dugo trajanje srednjeg vijeka, a kao višestoljetni identitetski simboli, ikone postaju još važnije u vrijeme obnove Katoličke Crkve nakon Tridentskog koncila. Upravo zbog svojega povlaštenog statusa u vjerskom životu kršćanskih zajednica i kontinuiteta povijesnog sjećanja koji se veže uz ikone, ikone su i identitetski simboli. Većina se i danas aktivno časti, pa is te strane zaslužuju znanstveno utemeljenu obradu koju pruža ova knjiga. 
Kako bi se razumjela teološka podloga čašćenja ikona, bilo je potrebno krenuti od početaka, od 6. stoljeća kada se javljaju prve legende o nerukotvorenim (acheiropoietos) ikonama. Zapisi o štovanju ikona postoje i iz ranijih razdoblja, ali intenzitet štovanja doseže kulminaciju u Bizantu 6. stoljeća od kada datiraju i najranije sačuvane ikone u riznici manastira sv. Katarine na Sinaju. Teološka promišljanja o razlozima i neophodnosti prikazivanja Kristova lika kao utjelovljenog Boga okupirala su bizantske teologe suočene s pojavom ikonoklazma. Teološke rasprave i razdori oko ikona potresali su 8. i 9. stoljeće, doba kad se kroz žučne rasprave stvarala i dozrijevala spoznaja ne samo o ikonama nego i teorija o mjestu i ulozi slike općenito. Nije prenapregnuto reći da se teorija slike stvarala putem odluka onodobnih crkvenih koncila i traktata napisanih u obranu ikona te da bi cjelokupni tok zapadne civilizacije bio bitno drugačiji da su u tim raspravama pobijedili ikonoklasti ili neka od kršćanskih hereza poput arijanske koja je u potpunosti odbacivala ikone, svece i relikvije. Najcjelovitiju teološku obranu ikona nalazimo u tri povezana traktata Ivana $\mathrm{Da}-$ maščanina (oko 675./76. - Mar Saba, 4. prosinca 749.), teologa koji nikada nije boravio na prostoru Bizanta nego svoju apologiju ikona piše u manastiru sv. Sabe nedaleko od Jeruzalema (što nije nevažno u kontekstu prisutnosti ikona izvan granica Bizanta). Ikone Krista branio je kao prikaze Bogočovjeka - Boga utjelovljenog u čovjeku. Sažeto rečeno, kao utjelovljenje Boga, Krist je i prva ikona. Možda i važnije za daljnju povijest kršćanske civilizacije, branio je likovna djela i s pozicije njihove nedjeljivosti od cjelokupnosti materijalne stvarnosti. Na prostoru bizantskog carstva, ali i šire, na prostoru Mediterana, od Jeruzalema do današnje Sirije, pod islamom se kroz ikone gradio i branio kršćanski identitet u vrijeme ranoga srednjeg vijeka, kao što je to bio slučaj i mnogo kasnije i na prostoru Dalmacije u vrijeme osmanskih osvajanja prostora Europe.

Za Zapad je posebno zanimljivo, kako ističe autorica, citirajući Robina Cormacka (Painting the Soul: Icons Masks and Shrouds, London, Reaktion Books, 1997.), da je pobožnost prema ikonama u zapadnoj crkvi gotovo nepromijenjena od 9. stoljeća, međutim, kako ističe Hans Belting (Likeness and Presence: A History of the Image Before the Era of Art, Chicago, University Press, 1994.), vrijeme početaka marijanske pobožnosti na Zapadu treba smjestiti u prvu polovinu
5. stoljeća kada su u Rimu postojale marijanske crkve s ikonama, pa je stoga primat bizantske crkve u razvoju marijanske pobožnosti putem ikona tek posljedica većeg broja izvora. Slikarstvo ikona razvijalo se „,bez etničkih granica, a bilo je dostupno svim kršćanima bez obzira na nacionalnost i kulturu“. Jednom izdvojene iz konteksta teoloških i liturgijskih pravila ortodoksije, ikone se stilski i ikonografski prilagođavaju zapadnom ukusu, ali zadržavaju mjesto u osobnoj pobožnosti i javnim kultovima koje su imale i u Bizantu. Ključne kvalitete ikona, njihova čudotvornost i sposobnost „civilne“ obrane u svojstvu braniteljica (paladija), ostaju jednake i na istoku i na zapadu. Svakako bih izdvojila poglavlje Javno štovanje ikona u kojem se rasvjetljavaju razlike izmedu bizantskog i zapadnog shvaćanja svetog lika u ikoni i postavljaju teze o konvergencijama i razilaženjima istočnog i zapadnog ikonopisanja. Rasprava u tom poglavlju potiče na razmišljanje o nama i njima, o bizantskoj duhovnosti i zapadnoj emocionalnosti. Po mišljenju autorice, estetsko-emocionalna kvaliteta ikona, a ne teološka dogma, omogućavala je popularnost i dugovječnost ikona u zapadnom kršćanstvu. Iako je neosporno da se zapadna ikona oslobada uvjeta preslikavanja čudotvornog prototipa i sve više daje na važnosti subjektivnosti i inovaciji umjetnika u humanizaciji prikazanog, zauzela bih se ipak za ponešto drugačije mišljenje, tj. da je emocionalni učinak ikona rezultat kompozicijskih strategija koje u osnovi ostaju jednake i u istočnom i u zapadnom slikarstvu. Mirovanje prikazanog (stasis) i redukcija osjetilne i prostorne stvarnosti u ikonama, te krajnja redukcija narativnosti obilježavaju najčašćenije ikone, i ne samo u Dalmaciji. Semantika ikona u osnovi računa na pojednostavljenje na ono bitno, izravnu i jezgrovitu komunikaciju između prikazanog i promatrača, na nadogradnju toga odnosa prema potrebama vjernika i na smirenu receptivnost prikazanog za molitve i molbe svih vrsta. Odnos prema prikazanom jest ugovorni, kako to biva od pamtivijeka između bogova i ljudi, o čemu nam govori i ova pjesmica:

Gospe moja od Dobrića

Providi mi šesnoga mladića,

Koji ne viče šije šete,

Koji ne igra na trašete,

Niti fuma španjulete.

Ako mi ga ti ne providiš

U crikvu me ti ne vidiš. 
Gospa od Dobrića na glavnom oltaru Gospine crkve na predjelu Dobrić u Splitu djelo je kretskog slikara kraja 15. i početka 16. stoljeća, a ova mala prijetnja Gospi primjer je interaktivnosti i recipročnog odnosa koji vjernik očekuje te glavno obilježje koje ikone razlikuje od svih drugih svetih slika. No time tek počinje rasprava o specifičnosti ikona. Ikone su krajnje tipizirana djela koje nadograđuju vjernici. U osnovi toga stoji želja vjernika da se, kako bi to protumačio Alfred Gell (Art and Agency: An Anthropological Theory, Clarendon Press, Oxford, 1998., ponovljeno izdanje 2010.), u umjetničkom djelu djelovanje umjetnika svede na minimum, a maksimalno omogući udio promatrača u stvaranju kultnog predmeta. O udjelu promatrača govori, po mojem sudu, najvažnije poglavlje knjige Javni kultovi u Dalmaciji gdje se donose brojni arhivski podaci o nadogradivanju zgotovljenoga umjetničkog djela po diktatu vjernika. Ikone se doslikavaju i preslikavaju, pa i nesmiljeno režu. Vjernici ikonu stvaraju i u konačnici posve mijenjaju putem brojnih intervencija: „Gotovo da nema ikone u Dalmaciji koja od 16. do 18. stoljeća nije pokrivena raskošnim srebrnim pokrovom oplate ili košuljice, koja otkriva lica i ruke kao semantički najvažnije dijelove“, piše autorica. Pokrovima i doslikavanjem atributa osuvremenjuju se kultovi, pa Hodigitrija postaje Gospa od Ružarija, a likovna forma transformira prema zahtjevu i razvoju kulta. Ikone se po pradavnom običaju za djela u javnim kultovima oblače u odjeću (vesturette), Krist u fine svilene tunike, a Bogorodica u haljinice koje su se i posebno nabavljale u Veneciji kao što je to učinio Hektor Hektorović za hvarsku „Gospu od Karmela“. Ikone se krune, kite Gospinim blagom, stavljaju na prijestolja, pokrivaju zavjetnim darovima. Svi važniji događaji u životu Dalmatinaca našli su sažeti prikaz u nekom od zavjetnih darova: vjerojatno je velik ulov rezultirao votivom u obliku velike srebrne ribe, bilo je i srdela, konjskih repova i potkova, volova, pušaka i polomljenog oružja, lanaca oslobođenika iz turskog ropstva, dijelova brodova, pored uobičajenih votiva ozdravljenih dijelova tijela. Sve su to dokazi čudotvornosti ikone što je i osnovni kriterij vrednovanja ikona i po tom načelu među 1200 najslavnijih ikona istoka i zapada u marijanski atlas Wilhelma Gumppenberga (1657.-1659.) ulaze i tri dubrovačke: „Gospa od Porata“, „Gospa od Kaštela“ i „Gospa de Breno" iz Župe dubrovačke. Pitanje je u kojoj su mjeri ikone umjetnička djela prema postrenesansnom shvaćanju toga pojma. Upravo, kako bilježi autorica, ,izraziti autorski izraz“ dijeli ikone od drugih autorskih Bogorodica s Djetetom u zapadnoj, konkretnije, toskanskoj umjetnosti. Ikone su najbliže relikvijama s kojima po mjerilu životnosti, odnosno shvaćanju žive prisutnosti prikazanog, dijele najviše sličnosti, a i po načinu čuvanja jer se često čuvaju iza zatvorenih vrata, unutar oltara, postaju slične relikviji u relikvijaru. Ikone, kao i svetačke moći, imaju, prema shvaćanju vjernika, svoju volju. One liječe, spašavaju, čuvaju stražu na zidinama grada, plaču, odbijaju se pomaknuti, otvaraju i zatvaraju zavjese, lete i plove, prate mornare na plovidbama, pozdravljaju se topovskom paljbom. Ukratko, shvaćaju se kao osobe u živoj interakciji s vjernicima.

Nije stoga neočekivano da javne kultove u Dalmaciji venecijanske vlasti nastoje posvojiti ulazeći time u intimu dalmatinskih zajednica, ali i zbog važnosti koju je Venecija davala Bogorodici od svoga utemeljenja, ikone su bile strogo kontrolirane kao i same zajednice koje iza njih stoje. „U zamahu kolonijalnog kozmopolitskog panvenecijanizma“ Mletačka Republika posvajala je ikone gradnjom svetišta ili obilježavanjem postojećih državnim grbom Lava sv. Marka. Događalo se, kao u slučaju Bogorodice „Nade Beznadnih“ iz franjevačkog samostana u Hvaru, da ikona u sjećanju jednog putnika po jadranskim obalama izgubi svoj lokalni identitet i bude zapamćena kao „Presveta Bogorodica Venecijanaca“. Ikone „Gospe od Pojišana“ i „Gospe od Prizidnice“ na Čiovu ulaze u kroniku (1761.) venecijanskog senatora Flaminija Cornera o ukazanjima i najslavnijim marijanskim ikonama na području venecijanske republike.

Poglavlje Ikone izmedu konvencije $i$ kreacije $u$ 13. i 14. stoljeću donosi podrobnu tipološku i stilsku analizu brojnih marijanskih ikona na prostoru Dalmacije. Najstarije datiraju u 13. stoljeće, a sve su redom Bogorodice s Djetetom. Čuvstveni odnos majke i djeteta iskustveni je odnos koji vjernici žele posvetiti i uzdignuti na oltar. Tvrdnja ima svoje uporište u teoriji slike, antropologa kulture, Alfreda Gella, čije postumno objavljeno djelo postaje nezaobilazno za shvaćanje pozicije slike u društvenim odnosima. Gell odbacuje semiotička tumačenja o arbitrarnosti znaka i tvrdi da se „ikonička reprezentacija temelji na stvarnoj sličnosti u formi između prikaza i prikazanih osoba ili za koje se smatra da su prikazane" bez obzira na shematiziranost i podspecificiranost prikazanog (Alfred Gell, cit. djelo, str. 25). Čast 
najstarije sačuvane marijanske ikone na povijesnom prostoru Dalmacije nosi „Bogorodica s Djetetom“ iz sv. Marije in Punta u Budvi koja je nastala oko 1200. godine. Izvedenice tipa Hodigitrije bile su najčešće, a nalazimo ih u Bogorodici „Nade Beznadnih“ iz franjevačkog samostana u Hvaru, ikoni „Madre della Consolazione“ $\mathrm{u}$ crkvi dominikanaca na Hvaru i drugdje. Glykofilousa koju karakterizira čvrst zagrljaj majke i djeteta najčešći je pak tip ranih ikona iz 13. stoljeća. Ovom prilikom bizantske tipove marijanskih ikona ne treba posebno tumačiti, dovoljno je reći da knjiga pruža jasna obrazloženja bizantskih prototipova u svojim talijanskim i dalmatinskim inačicama što će biti vrlo korisno čitateljima jer su običaji imenovanja ikona (apelacije) po značenju u kultu, a ne nužno po izvornom tipu složeni i često nerazumljivi laicima. Autoričina analiza hvarske, „Hektorovićeve“ ikone podrijetlom s Biševa, poznate kao „Gospa od Karmena“ s kraja 13. stoljeća, svojevrsni je tour de force stilske analize u koju je uključeno dvadesetak komparativnih djela. Datiranje toga djela već je Gamulin istaknuo kao ključno pitanje romaničkog slikarstva u Dalmaciji, pa se i autorica vraća na to sporno mjesto i smješta „Gospu od Karmena“ u posljednju četvrtinu 13. stoljeća, otprilike u isto vrijeme kao i splitsku „Gospu od Zvonika“ i zadarsku iz crkve sv. Šime, kvalificirajući je ipak kao njihovu „manirističku izvedenicu“. U zaključku, autorica se dotiče i adriobizantinizma kao odrednice koja uobičajeno objedinjuje sva djela koja, kao i „Gospa od Karmena“, nemaju jasne odlike mletačkog, firentinskog, pizanskog ili sijenskog slikarstva te zaključuje da ,slike na dasci 13. stoljeća u Dalmaciji nemamo razloga zvati adriobizantskim " $\mathrm{i}$ predlaže ,jadranski benediktinski slikarski krug“ kao točniju odrednicu barem što se tiče ikonografije. Niti s ikonama 14. stoljeća slika stilskih razmjena unutar internacionalne struje mletačkog trecenta nije mnogo jasnija jer, kako upozorava autorica, pokazuju se i sličnosti s kretskim i ciparskim ikonama. Uočavanje kretske komponente autorica zahvaljuje izvrsnom poznavanju kretsko-venecijanskih ikona iz kasnijih razdoblja čemu posvećuje posebno poglavlje. Tema je zahtjevna jer kretsko-venecijanska produkcija od 15. do 17. stoljeća do sada nije bila u žiži povjesničko-umjetničkog interesa iako je riječ o najbrojnijoj skupini dalmatinskih ikona u ovim stoljećima. Radi se o specifičnoj produkciji postbizantskog razdoblja ograničenoj uglavnom na ikone što je smješta mimo glavnih tokova umjetničke produkcije toga vremena. Zahvalni smo i na pojašnjenjima vezanim uz problem retardacije stila u 18. stoljeću koje, ipak, donosi nove teme (ikone sv. Spiridona), novi tip ikone (Bogorodice Skopiotisse) i novu slikarsku školu (školu jonskih otoka) čemu je posvećeno posljednje poglavlje.

U konačnici valja naglasiti da se ikone u hrvatskoj povijesti umjetnosti do sada nisu proučavale sveobuhvatno, tako da se uz stilsko i ikonografsko značenje pojedinih ikona obuhvate i neki aspekti hierotipije - novi termin i prijedlog A. Lidova za istraživanje oblikovanja i funkcije sakralnih prostora u svim oblicima pojavnosti. Malu kritiku treba uputiti izdavaču i uredničkom zboru jer je knjiga zaslužila i kazalo pojmova, potkrale su se i pogreške u brojevima ilustracija, duže citate iz arhivskih tekstova moglo se dati stručno prevesti ili prepričati, a poneku bilješku premjestiti u tekst. Katalog svih poznatih dalmatinskih ikona do početka 20. stoljeća međutim je iscrpan $\mathrm{s}$ bogatom prijašnjom literaturom koja se stanjuje kako se stoljeća odmiču jer su kasnije ikone, osim samoj autorici, bile slabo ili nimalo poznate, dok većina ikona sv. Spiridona iz 18. stoljeća nikada do sada nije bila objavljena. Knjiga je bez sumnje referentno djelo za sva daljnja istraživanja domaćih i stranih istraživača. Za hrvatsku povijest umjetnosti ove složene tematike, knjiga Javni kultovi ikona u Dalmaciji učinila je ono što je magistralna knjiga Bild und Kult Hansa Beltinga iz 1990. godine učinila za razvoj svjetske bizantologije. 